\section{A Long-term Study on Native Variation of Flowering and Fruiting in Spur-type 'Delicious' Apple}

\author{
Martin J. Bukovac ${ }^{2}$, Paolo Sabbatini, and Franco Zucconi ${ }^{1}$ \\ Department of Horticulture, Michigan State University, 390 PSSB, East \\ Lansing, MI 48824-1325
}

Phillip G. Schwallier

Clarksville Horticultural Experiment Station, Michigan State University, 9302 Portland Road, Clarksville, MI 48815

Additional index words. biennial bearing, flower initiation, Malus domestica Borkh., Redchief, return bloom

\begin{abstract}
Alternate cropping is a common physiological trait in several important apple cultivars, including spur-type 'Delicious'. Alternate bearing usually develops slowly in apple trees as they mature, but may be dramatically induced by environmental or biotic stresses. We describe the native temporal and within-year variation of bloom and yield of a highly uniform spur-type 'Delicious'/M.106 population $(n=95)$ over a period of 9 years. Crop load was adjusted by hand in the first year to establish a defined normal fruit population distribution. Thereafter, all trees received identical practices. Bloom density (BD) was rated (1 to 10) and yield and fruit size distribution were determined annually on an individual tree basis. Temporal profiles for bloom and yield had four periods above and below the general mean (GM). There were two 3-year periods of nonbienniality. Annual variation in BD ranged from 3.1 to 8.0 and in yield from 54 to $168 \mathrm{~kg} /$ tree. Variation in cropping was greater when expressed as percentage deviation from the GM. Annual mean fruit weight was inversely related to yield, but percentage of small- (51 to 64 mm) or large-diameter fruit (70 to $82 \mathrm{~mm}$ ) was not consistently related to yield. The within-year $\mathrm{CV}$ ranged from $\approx 11 \%$ to $66 \%$ for $\mathrm{BD}$ and from $13 \%$ to $42 \%$ for yield. The degree of synchrony (within-year variation) was lowest in the year after crop adjustment (to normal distribution), became highly synchronized in $\approx 4$ years, and then decreased. The relationship of native variation of individual trees to the population and to flower initiation and fruiting are discussed in relation to the alternate bearing cycle and significance in selecting trees for experimentation.
\end{abstract}

Irregular flowering and fruiting is a common trait in polycarpic woody species (Kelly and Sork, 2002; Monselise and Goldschmidt, 1982). This phenomenon is usually termed alternate (irregular, biennial) bearing in horticultural plants and masting, defined as intermittent production of large crops of fruit/ seed by a population, in forest trees. Both have similar characteristics and have been studied extensively. In forest trees, masting has significant ecological implications on

Received for publication 1 Sept. 2009. Accepted for publication 19 Oct. 2009.

Partial funding for these studies was provided by the Michigan Apple Research Committee, Lansing, MI; Mr. John Amos, Amos Farms, Williamsburg, MI; and the Michigan Agricultural Experiment Station, East Lansing, MI.

We appreciate the assistance of Jerome Hull, Gail Byler, John Gilmore, Royal Fader, and Denise Ruwersma in collecting bloom and yield data and of Dr. A.N. Kravchenko for consultation on statistics.

${ }^{1}$ Present address: Department of Plant Production and Environmental Science, Marche Polytechnic University, 60131 Ancona, Italy.

${ }^{2}$ To whom reprint requests should be addressed; e-mail bukovacm@msu.edu. pruning, rootstock, vigor, shoot growth, and most climatic factors, except temperature, were not conclusively related to the alternate bearing pattern (Drain, 1924; Singh, 1948b). Irregular cropping was related to cultivar and temperature during flower and fruit development (Jackson and Hamer, 1980) and the tendency was greater in spur- than nonspur-type trees (Jonkers, 1979; Monselise and Goldschmidt, 1982). Early defoliation in "on" years, within 6 weeks after bloom, reduced flower initiation (Aldrich and Fletcher, 1932; Davis, 1957; Fulford, 1960); removal of blossom clusters, flowers, or fruitlets, within 4 to 6 weeks after bloom, in "on" years increased flower initiation in the "on" year and fruiting in the following "off" year (Bobb and Blake, 1938; Harley et al., 1935, 1942).

The finding that removing flowers or fruit early in the "on" year increased flower initiation was significant because the observation not only provided the basis for commercial blossom and fruit thinning practices for minimizing the alternate bearing problem, but also confirmed that lack of flower initiation, and not fruit set, was the most frequent limiting factor (Singh, 1948b). Also, these studies focused new research on the role of developing fruit and fruit seed content on flower initiation, which has provided convincing data that the seeds are the source of hormones (e.g., gibberellins) that inhibit flower initiation (Dennis and Neilsen, 1999; Hedden et al., 1993; Hoad, 1978; Luckwill, 1977). The observation by Guttridge (1962) that exogenously applied gibberellic acid inhibited flower initiation in apple further supported the proposed role of gibberellin. Exactly how the seed-produced gibberellins are involved in alternate bearing remains to be clarified.

With few exceptions, most apple studies have been short term (mostly one "on/off" cropping cycle) and have focused on temporal variation of irregular cropping (yield) (Brown, 1942; Harley et al., 1942; Jackson and Hamer, 1980). However, variation in flowering and fruiting in a given alternate bearing population has at least two major components: 1) variation within a single year (synchrony) and 2) year-to-year variation (temporal). Within-tree variation is potentially a third component; alternate bearing can be induced in selected limbs on the same tree, and this condition may persist for several years (Drain, 1924; Harley et al., 1935). Also, not all spurs on a given tree are synchronized. Some portion of the spur population may be flowering, whereas others are barren.

Surprisingly, in contrast to masting studies in forest trees (Lombardo and McCarthy, 2008; McCarthy and Quinn, 1989), withinyear variation of flowering/fruiting has received little attention in apple (Monselise and Goldschmidt, 1982). The within-year variation component may be significant in irregular flowering because not all trees in an alternate-bearing apple orchard are synchronized (Davis, 1957; Drain, 1924; Jonkers, 
1979). Flowering is generally a characteristic of an individual tree. Thus, in any given population (orchard), the "on"-year flower density may vary markedly.

The objectives of our long-term study were to: 1) define both temporal and withinyear variation of flowering and fruiting in a highly uniform, spur-type 'Delicious' apple population growing under identical soil, climatic, and cultural conditions; 2) relate effects of irregular cropping on flower initiation, fruit set, and partitioning into selected fruit size classes; and 3) discuss the importance of the variance of trees with selected flower densities as experimental units for research purposes.

\section{Materials and Methods}

Experimental site and general conditions. A Redchief 'Delicious' M.106 (M.106) spurtype orchard was established $(3.0 \times 6.0 \mathrm{~m})$ in 1981 on a virgin orchard site of Riddle sandy loam soil at the Clarksville Horticultural Experiment Station, Clarksville, MI. Trees were trained to a central leader and dormantpruned annually to maintain comparable canopies. Water sprouts, if excessive, were removed in late summer. The orchard floor was maintained in sod (kentucky blue grass/ creeping red fescue/perennial rye grass; $\approx 40 \% / 40 \% / 20 \%$ ) with a glyphosate, herbicide strip $(\approx 2.5$ to $3.0 \mathrm{~m})$. Trickle irrigation was provided as needed. Pertinent temperature data were recorded by an automated weather station located on the site (Table 1). Five beehives were provided per hectare and pollen from several other compatible cultivars was present in the same orchard to ensure fruit set.

History and plot preparation. Trees selected for our study were previously (1988 to 1998) used for photosynthesis, fruit growth, fruit thinning, preharvest drop, and fungicide studies. During this period, the orchard developed a significant irregular bearing pattern. In 1998, 96 trees (32 in each of three north-south rows) were selected for a longterm (9-year) study. These trees were fully developed, uniform in size and canopy structure, and in a moderately "on" year producing $110 \mathrm{~kg} /$ tree. We rated fruit set on all trees and then selected or adjusted (immedi- ately after June drop) the crop load to establish a tree population with a defined and normally distributed crop load (Fig. 1). For the remainder of the study, all trees received identical cultural practices, mainly $\approx 330 \mathrm{~kg} \cdot \mathrm{ha}^{-1} 19 \mathrm{~N}-19 \mathrm{P}-19 \mathrm{~K}$ per year, pruning, crop protection (recommended Integrated Pest Management program), preharvest drop control, and irrigation. No crop adjustment was performed after the initial year (1998). A postbloom frost in 2002 may have reduced yield but had no effect on bloom ratings. No other significant frost or environmental event occurred during our study.

Data collection. The date of full bloom (FB) was recorded annually (Table 1). Bloom density (BD or BDR) was rated each year by five to seven horticulturists (five being the same individuals each year) on a scale of 1 (lowest) to 10 (highest). The rating was based on a visual estimate of the percentage of the total spurs bearing flowers, each BD unit equaling $10 \%$. In this report, we view the terms flower initiation and bloom as synonymous because our bloom rating was used as an index of flower initiation in the previous season.

Yield (total weight) per tree was determined at the time of commercial harvest. Sound, dropped fruit, if significant, were collected and included with the yield data. The harvested fruit from each tree was sized into the following classes: less than 51, 51 to 56,57 to 64,65 to 69,70 to 75,76 to 82 , greater than $82 \mathrm{~mm}$ using a Greefa grader (Tricht-Geldermalen, Holland). Fruit size distribution histograms were prepared based on percentage of fruit (wt. basis) in each size class. Because all of these data were collected on each tree, and the same trees were used each year, sampling error was eliminated. The $\mathrm{CV}$, calculated on individual trees and on annual means, provided information on the relationships of population $\mathrm{CV}$ to individual tree variability and synchrony (Buonaccorsi et al., 2003).

The number of fruit in each class was estimated by dividing the weight of the fruit by the mean weight of 100 randomly selected fruit from the respective classes. The sum of the number of fruit per class was used as an estimate of the total number of fruit per tree.

Table 1. Dates of full bloom, growing degree days (GDD), and the minimum and maximum temperatures during bloom.

\begin{tabular}{lcccc}
\hline & & & \multicolumn{2}{c}{ Temp. $\left({ }^{\circ} \mathrm{C}\right)$} \\
\cline { 3 - 5 } Date of full bloom & GDD $^{\mathrm{z}}$ to full bloom & GDD $^{\mathrm{y}}$ Full bloom $+10 \mathrm{~d}^{\mathrm{y}}$ & Minimum & Maximum \\
\hline 5 May 1999 & 102.3 & 58.5 & 2.3 & 26.3 \\
4 May 2000 & 94.8 & 76.6 & 3.2 & 29.1 \\
6 May 2001 & 125.6 & 52.4 & -2.3 & 25.8 \\
9 May 2002 & 110.8 & 13.2 & 1.7 & 21.4 \\
13 May 2003 & 118.6 & 36.6 & 3.5 & 23.2 \\
7 May 2004 & 109.9 & 74.3 & 1.6 & 28.1 \\
8 May 2005 & 109.1 & 34.5 & 1.3 & 23.6 \\
8 May 2006 & 111.1 & 88.0 & 0.9 & 28.2 \\
9 May 2007 & 128.4 & 54.8 &
\end{tabular}

${ }^{\mathrm{z}}$ Growing degree days (GGD base $10{ }^{\circ} \mathrm{C}$ ) calculated from 1 Mar. to full bloom date.

${ }^{\mathrm{y}}$ Growing degree days (GDD base $10^{\circ} \mathrm{C}$ ) calculated from full bloom date plus $10 \mathrm{~d}$. The mean annual date of full bloom occurred on accumulation of $112 \pm 11$ GDD after 1 Mar.

HortScience Vol. 45(1) JanUary 2010

The number of nonaborted seeds per fruit was determined on the random size class samples used as stated previously, and the mean seed number per fruit was used to calculate total seed per class and total seed per tree.

A flower initiation index was calculated by dividing the BDR by the previous season yield ( $\mathrm{kg} /$ tree) and multiplying by 1000 . The multiplier represented the number of flowers estimated for each BDR on identical, adjacent trees in the same orchard (Bukovac et al., 2006). A fruit set factor was calculated by dividing the BDR by yield $(\mathrm{kg} / \mathrm{tree})$ in the same year.

The degree of alternation of cropping was assessed by calculating the constant I as developed by Hoblyn et al. (1936). This constant describes the intensity of fluctuation in a given cycle. The difference in yield over 2 consecutive years divided by their sum, ignoring negative signs, gives the constant I. The higher the index value, the greater the alternation.

Tree growth during the course of the experiment was indexed by measuring the trunk diameter in 6 of the 9 years, including the first and the last year of the study. Values for the 3 intervening years were calculated using a regression equation based on the data from the six annual measurements.

Statistics. Basic statistics and regression analysis were performed using SAS (SAS Institute, Cary, NC) or Sigma Plot (SPSS, Chicago, IL) programs. The significance of the $\mathrm{CV}$ has been critically evaluated and adopted as an important statistic in measuring variation in seed production in forest ecology (Herrera, 1998; Koenig et al., 2003; McArdle and Gaston, 1995). To evaluate within-year variation and population synchrony, we calculated the $\mathrm{CV}$ for individual trees, and the population $\mathrm{CV}$ was calculated using the mean annual CV values (Buonaccorsi et al., 2003; Herrera, 1998). Thus, using the same statistics here permits comparison with data from related studies, particularly on nut crops. One

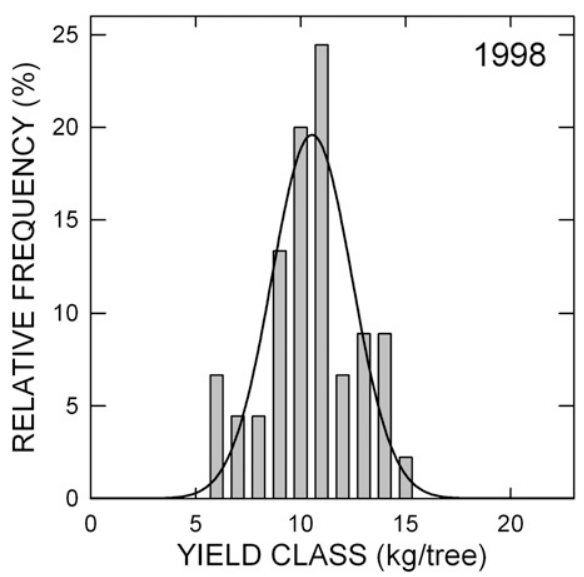

Fig. 1. Relative frequency distribution of the tree population (each class represents $5 \%, \approx 12 \mathrm{~kg}$ / tree, of the highest yield, $242 \mathrm{~kg} /$ tree) after adjusting crop load at June drop at the beginning of the study (1998). 
Table 2. Basic statistics describing the annual variation of flowering and fruiting of 'Delicious' apple over the course of the study (1998-2007).

\begin{tabular}{|c|c|c|c|c|c|c|c|c|c|c|c|c|}
\hline \multirow[b]{2}{*}{ Year } & \multicolumn{6}{|c|}{ Bloom density rating $z, y$} & \multicolumn{6}{|c|}{ Yield $(\mathrm{kg} / \text { tree })^{\mathrm{z}}$} \\
\hline & Mean & Median & $\mathrm{CV}$ & $\mathrm{I}^{\mathrm{x}}$ & $\begin{array}{l}\text { Deviation } \\
\text { from } \mathrm{GM}^{\mathrm{w}} \\
(\%)\end{array}$ & $\begin{array}{c}\text { Deviation } \\
\text { from previous } \\
\text { year }(\%)\end{array}$ & Mean & Median & $\mathrm{CV}$ & $I^{x}$ & $\begin{array}{l}\text { Deviation } \\
\text { from } \mathrm{GM}^{\mathrm{w}} \\
(\%)\end{array}$ & $\begin{array}{c}\text { Deviation } \\
\text { from previous } \\
\text { year }(\%)\end{array}$ \\
\hline 1998 & $-^{\mathrm{v}}$ & - & - & - & - & - & $109.5 \pm 22.1$ & 109.5 & 20.2 & - & 5.8 & - \\
\hline 2000 & $6.3 \pm 1.8$ & 6.5 & 28.8 & 0.33 & 9.9 & 99.3 & $150.1 \pm 28.6$ & 156.2 & 19.1 & 0.19 & 45.0 & 48.4 \\
\hline 2001 & $5.5 \pm 2.0$ & 5.8 & 35.8 & 0.06 & -3.4 & -12.1 & $69.4 \pm 24.2$ & 70.6 & 34.9 & 0.37 & -33.0 & -53.8 \\
\hline $2002^{u}$ & $5.6 \pm 2.0$ & 6.3 & 36.4 & 0.01 & -2.4 & 1.0 & $53.5 \pm 22.5$ & 54.0 & 42.1 & 0.13 & -48.4 & -23.0 \\
\hline 2005 & $7.0 \pm 0.8$ & 7.0 & 11.4 & 0.31 & 22.6 & 89.1 & $103.1 \pm 23.3$ & 99.5 & 22.6 & 0.25 & -0.4 & 67.2 \\
\hline 2006 & $7.4 \pm 1.1$ & 7.5 & 15.2 & 0.03 & 29.2 & 5.4 & $167.7 \pm 24.3$ & 166.4 & 14.5 & 0.24 & 62.0 & 62.6 \\
\hline 2007 & $4.8 \pm 1.6$ & 4.6 & 33.8 & 0.21 & -16.1 & -35.1 & $-^{\mathrm{v}}$ & - & - & - & - & - \\
\hline
\end{tabular}

$\mathrm{z}_{\mathrm{n}}=95$.

'Bloom density rating from 1 to 10 (highest); see text for details.

${ }^{\mathrm{x}} \mathrm{I}=$ Index of alternation (Hoblyn et al., 1936). The constant I describes the intensity (fluctuation) of alternation. A numerical value is obtained by calculating the difference in yield between 2 consecutive years and dividing by their sum without considering negative signs.

${ }^{\mathrm{w}} \mathrm{GM}=$ general mean $\pm \mathrm{SD} 5.7 \pm 1.5$ for bloom rating and $103.5 \pm 24.5$ for yield per tree.

'Data not collected.

"Postbloom frost may have affected yield, but not bloom data.

tree was damaged during the course of the experiment in an equipment mishap; all data from this tree were deleted from the study.

\section{Results}

Temperature. The date of FB in 7 of the 8 years varied by $6 \mathrm{~d}$ (4 to 9 May) and in the remaining year, FB occurred on 13 May (Table 1). The mean annual date of FB occurred on accumulation of $112 \pm 11$ growing degree days (GDD). Yield was significantly correlated $(r=0.62, P<0.06)$ with the number of GDD during the bloom period, i.e., date of FB plus $10 \mathrm{~d}$ (Tables 1 and 2).

The minimum temperature during the bloom period, in 7 of the 8 years, varied between 0.6 and $3.5^{\circ} \mathrm{C}$ (Table 1). In 2002, the minimum temperature was $-2.3{ }^{\circ} \mathrm{C}$ on $\mathrm{FB}+$ $10 \mathrm{~d}$ and $-1.8^{\circ} \mathrm{C}$ on the next day, which may have resulted in a reduction of fruit set and yield. Although the yield in 2002 was the lowest during the study $(53.5 \mathrm{~kg} /$ tree $)$, there were two additional frost-free years (minimum temperature of 0.6 and $3.5^{\circ} \mathrm{C}$ ) with low yields, e.g., 2001 and 2004, with 69 and 62 $\mathrm{kg} /$ tree, respectively (Tables 1 and 2).

Annual variation in flowering and yield. The marked differences in annual mean values for bloom and yield confirmed the irregular cropping pattern of our tree population (Table 2). Mean annual BD varied from 3.1 to 8.0 and mean yield from 54 to 168 $\mathrm{kg} /$ tree, a 2.6-fold difference in BD and 3.1fold difference in yield, respectively (Table 2 ). The variations in flowering and cropping were more pronounced when expressed as percentage deviation from the population mean or percentage change from the previous year (Table 2). The year-to-year variation from the general mean ranged from $-45 \%$ to $+40 \%$ for BD and from $-48 \%$ to $+62 \%$ for yield. An even greater change was apparent relative to the deviation from the previous season, namely $-54 \%$ to $+99 \%$ for $\mathrm{BD}$ and $-54 \%$ to $+116 \%$ for yield (Table 2 ). Using the $\mathrm{CV}$, within a given year, as the measure of variability, the $\mathrm{CV}$ ranged from $11.4 \%$ to $65.9 \%$ for BD and from $13.4 \%$ to $42.1 \%$ for

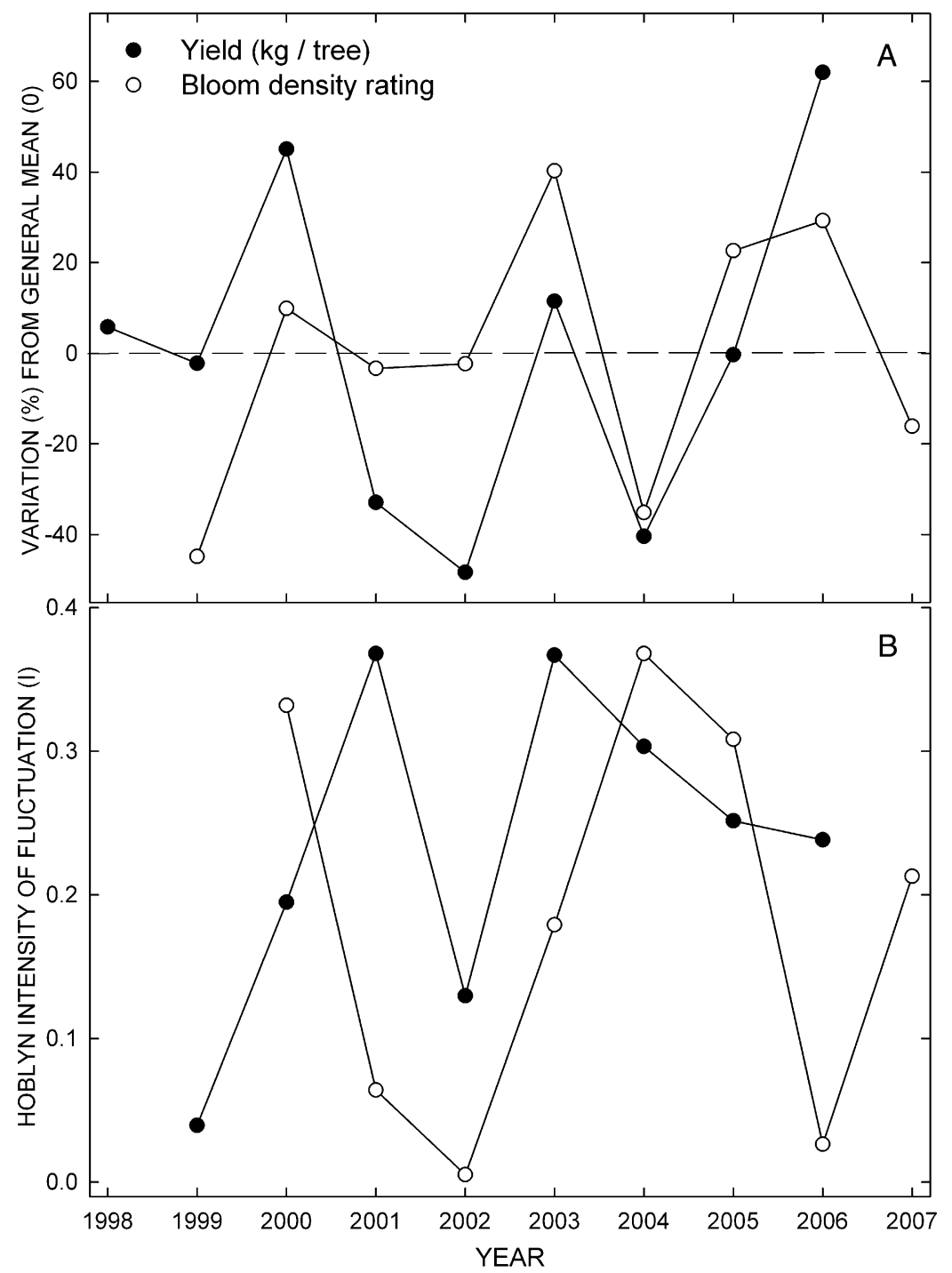

Fig. 2. Profiles of mean annual variation of bloom density and yield relative to the general mean (A) and the intensity of fluctuation calculated by the Hoblyn procedure $(\mathbf{B})$. The general mean \pm SD for bloom density was $5.7 \pm 1.0$ and $103.5 \pm 24.5$ for yield.

yield (Table 2). In general, the range in $\mathrm{CV}$ was greater for BD than for yield, but the mean annual $\mathrm{CV}$ for the two were similar
( $\approx 31 \%$ versus $27 \%$ ), indicating greater temporal variation in BD than in yield (Table 2). The CVs for the tree population above the 
general mean, for BD and yield, were identical $(16.8 \%)$; however, for the tree population below the general mean, the $\mathrm{CV}$ for $\mathrm{BD}$ $(42 \%)$ was 1.2 -fold greater than that for yield $(35 \%)$.

The temporal profiles for BD and yield over the entire study show four periods of BD and yield above and five on or below the general mean $(5.7 \pm 1.5 \mathrm{BDR}, 103.5 \pm 24.5$ kg/tree) (Table 2; Fig. 2A). There were two 3year periods of insignificant biennial alternation in both BD and yield (Fig. 2A). In 2002, yield, but not $\mathrm{BD}$, may have been reduced by a postbloom frost (Table 2; Fig. 2A). The intensity of annual fluctuation (I) (Hoblyn et al., 1936) ranged from 0.01 to 0.37 for $\mathrm{BD}$ and from 0.04 to 0.37 for yield (Fig. 2B; Table 2).

Tree growth. There was a weak inverse relationship between yield and annual increase in trunk diameter. The mean trunk diameter of the tree population $(n=95)$ increased from $15.6 \pm 1.1 \mathrm{~cm}$ in the initial year to $19.4 \pm 1.0 \mathrm{~cm}$ in the last year of the study (data not presented). However, regression of annual increase in trunk diameter on yield, either in the same or the next year, was not significant.

Fruit size. The temporal profile for annual mean fruit weight was inversely related to yield in all years, except for 2005 (Fig. 3A). Using percentage of fruit in size classes 51 to $64 \mathrm{~mm}$ as an index of small, low-value fruit and the percentage in size classes 70 to 82 $\mathrm{mm}$ as an index of large fruit (commercially desired), we found no significant correlation between yield and fruit size. This cultivar produced an average of only $2.6 \%$ small fruit in 6 of the 8 years and only $5.1 \%$ small fruit when data for all 8 years were included (Fig. $3 \mathrm{~B})$. In contrast, $62 \%$ of the total fruit yield over all years was in the commercially desired size classes of 70 to $82 \mathrm{~mm}$ in 5 years and $48 \%$ to $56 \%$ in the remaining 3 years. The remaining fruit were in size classes less than $50 \mathrm{~mm}$, greater than $82 \mathrm{~mm}$, or 65 to 69 $\mathrm{mm}$. The CV was high (110\%) for percentage of small fruit, primarily because of the presence of the large amount of small fruit in 2 (2002 and 2003) of the 8 years (Fig. 3B). In contrast, the annual variation percentage of large fruit was low, namely $14.5 \%$, confirming consistent and uniform yields in the 70- to $82-\mathrm{mm}$ size classes in the absence of thinning (Fig. 3B).

Comparing the percentage distribution of small and large fruit in low-yielding trees, i.e., trees yielding less than the general mean, with high yielding trees in the population $(\mathrm{n}=$ $95)$, we found 10 -fold more large than small fruit $(6.6 \%$ versus $67.1 \%)$ in the low-yielding population and only twofold more $(26.3 \%$ versus $53.4 \%$ ) in the high-yielding trees.

Flower initiation relative to fruit mass, number, and seed content. For the entire population over all years, flower initiation (BD) was inversely related, linearly, to total mass, number of fruit, and number of seeds per tree. Based on the coefficient of determination, $39 \%$ of the total sums of squares was associated with yield, $52 \%$ with fruit number,

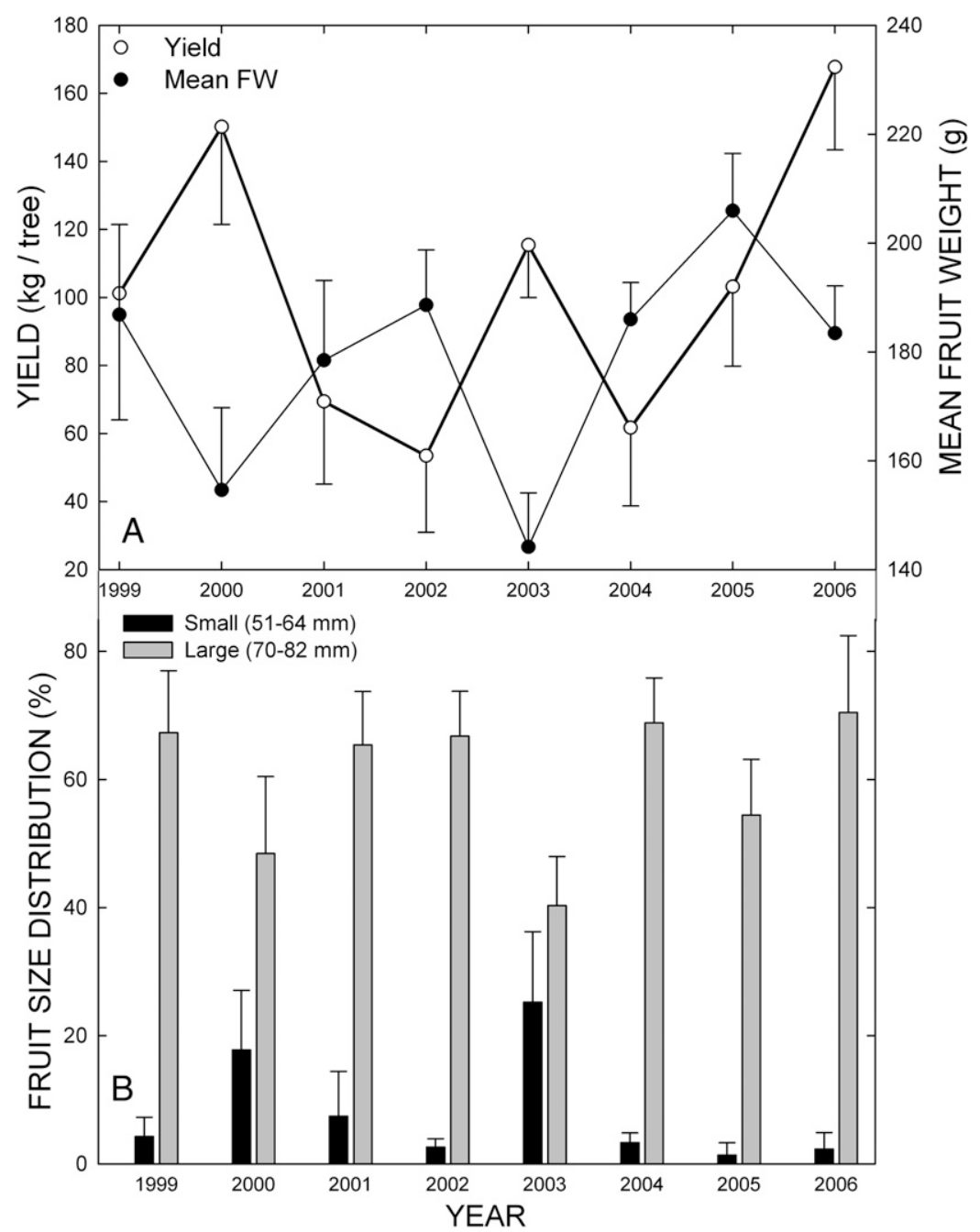

Fig. 3. Yield and mean fruit weight profiles (A) and fruit size distribution of small and large fruit over 8 consecutive years (B). Sixty-seven percent of the total yield was represented in these two classes. Bars represent SD.

and $43 \%$ with seed number per tree. Corresponding linear regression equations for flower initiation were $\mathrm{Y}=-0.020 \mathrm{x}+8.30$ $(P=0.099)$ on fruit mass:

$$
\begin{aligned}
\mathrm{Y}= & -0.004 \mathrm{x}+8.19(P=0.043) \text { on fruit } \\
& \text { number and } \\
\mathrm{Y}= & -0.0007 \mathrm{x}+8.20(P=0.076) \text { on seed } \\
& \text { number per tree. }
\end{aligned}
$$

Within-year variation. Within-year variations for BD and yield were normally distributed, except BD in 1999 (Fig. 4A). The mean:median ratios were uniform and near 1.0. The mean deviation from 1.0 for all 8 years was only 0.035 for $\mathrm{BD}$ and 0.019 for yield. In two cases for both BD and yield, the maximum deviations were 0.07 (BD) and 0.04 (yield). Furthermore, calculated normal distribution curves of individual tree data confirmed normal distribution populations, and, with one exception, all distribution curves were symmetrical (Fig. 4).

We observed significant variation in central tendency, range, and skewness of the within-year population for both $\mathrm{BD}$ and yield
(Fig. 4). Examples of extremes in central tendency are illustrated for BD in I versus $\mathrm{K}$ and for yield in $\mathrm{H}$ versus $\mathrm{P}$ (Fig. 4). Mean values for $\mathrm{BD}$ units and yield varied from 3.1 to $8.0 \mathrm{BD}$ and from 54 to $168 \mathrm{~kg} /$ tree, respectively. Within-year dispersion, measured by the range, varied 2.1-fold (range, 3.8 to 8.1 ) for BD and 2.6-fold (range, 62 to 159) for yield. All skewness coefficients were less than one, except for BD in 1999 (Fig. 4A). Interestingly, all skewness coefficients for bloom were negative, except for 1999, and all but two were positive for yield (Figs. 4D and F). The greatest variability in these three parameters occurred in the 1999 population (Fig. 4A-B). This was the year after the adjustment of the crop load at the beginning of the study (1998). The range and skewness of the within-year profiles were reduced in the postfrost years (2003 to 2006) compared with the prefrost years (1999 to 2001).

The degree of synchrony, based on within-year mean CVs, was similar for BD and yield (30\% versus $28 \%$ ) (Figs. $5 \mathrm{~A}$ and C). However, synchrony was greater in the population above than below the mean by 


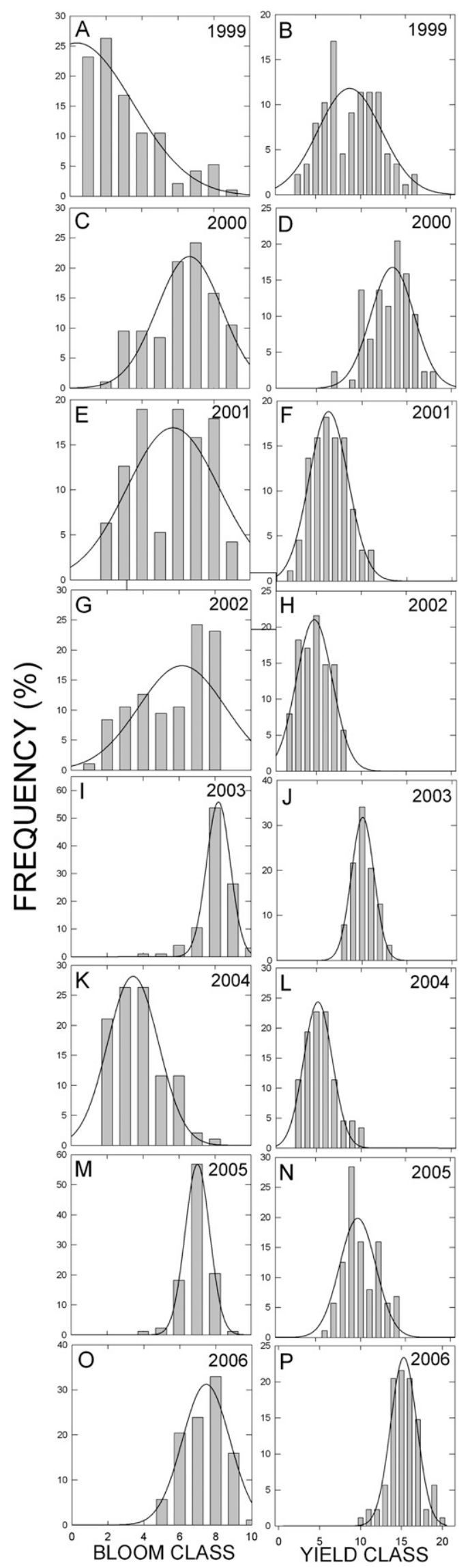

Fig. 4. Relative frequency histograms illustrating within-year native distribution of bloom density (left) and yield (right) of a 'Delicious' apple tree population growing under identical environmental conditions and cultural practices. Each bloom class (1 to 10) represents $10 \%$ of highest bloom rating (10) and each yield class $(\mathrm{kg} / \mathrm{tree})$ represents $5 \%(\approx 12 \mathrm{~kg})$ of highest yield. $\approx 2.2$ - to $\approx 2.6$-fold for yield and $\mathrm{BD}$, respectively. Variation in BD of the tree population in the first 4 years (1999 to 2002), immediately after adjusting crop load to a normal distribution and in 2004, was the highest in the study (Fig. 5B). Bloom was highly synchronized in 2003, 2005, and 2006 with the lowest standard deviation and $\mathrm{CV}$ (Fig. 5A). There were few outliers. The degree of synchrony varied but generally followed the year-to-year cropping pattern during this period. Because the bloom data were collected before the frost in 2002, they were not compromised.

In general, there was greater synchrony in yield than in BD (Fig. 5). Variation in yield in the first year of study was high with a SD of 36.5 and a $\mathrm{CV}$ of $37 \%$. The highest level of synchrony occurred in 2000, 2003, and 2006 with CV less than $20 \%$ and high parallelism in individual tree profiles (Fig. 5D). The yield profiles in the other years still exhibited parallelism but with greater variation ( $\mathrm{CV}$ of $23 \%$ to $42 \%$ ). There were few outliers. Variation in the 3 years preceding the frost (2002) was higher than the immediate postfreeze 3-year period (mean cv 30\% versus 24\%). Synchrony was the lowest in 2002 (frost year) and highest in the next year.

Analysis of subpopulations selected for high or low synchrony in Year 1 of 3-year cropping cycles revealed a close relationship between synchrony and annual cropping patterns (Fig. 6). A strong biennial cropping pattern was associated with high synchrony (CV 21\%) and low-yielding trees in both cropping cycles (Fig. 6A). A similar response was found in the first cycle (Year 1 to 2) of the synchronized, high-yielding subpopulation, but less so in the second cycle (Fig. 6B). Synchrony decreased in Year 2 (cv 40\%) and the yield was only slightly greater in Year 3 . The subpopulation selected for low synchrony (CV 41\%) remained asynchronous during the next 2 years (Fig. 6C). Some trees in this population had higher and others lower yields in Years 2 and 3, resulting in more uniform cropping. The intensity of alternation was also closely related to synchrony; Hoblyn I was 0.57 to 0.64 in the highly synchronized trees (Fig. 6A-B) and lower (range, 0.11 to 0.28 ) in the asynchronous populations (Fig. 6B-C).

\section{Discussion}

Many apple cultivars develop a pronounced irregular cropping pattern that leads to inefficient crop production. This phenomenon has been studied intensively by focusing on short-term (one or two cropping cycles) methods for increasing yield in the "off year" (Singh, 1948a). Long-term studies on biennial cropping and the variation in apple tree populations have been limited (Monselise and Goldschmidt, 1982). Most long-term studies were not based on welldefined tree populations, but on yield data generated in related studies or on regional or countrywide production statistics (Hoblyn et al., 1936; Jackson and Hamer, 1980). We 

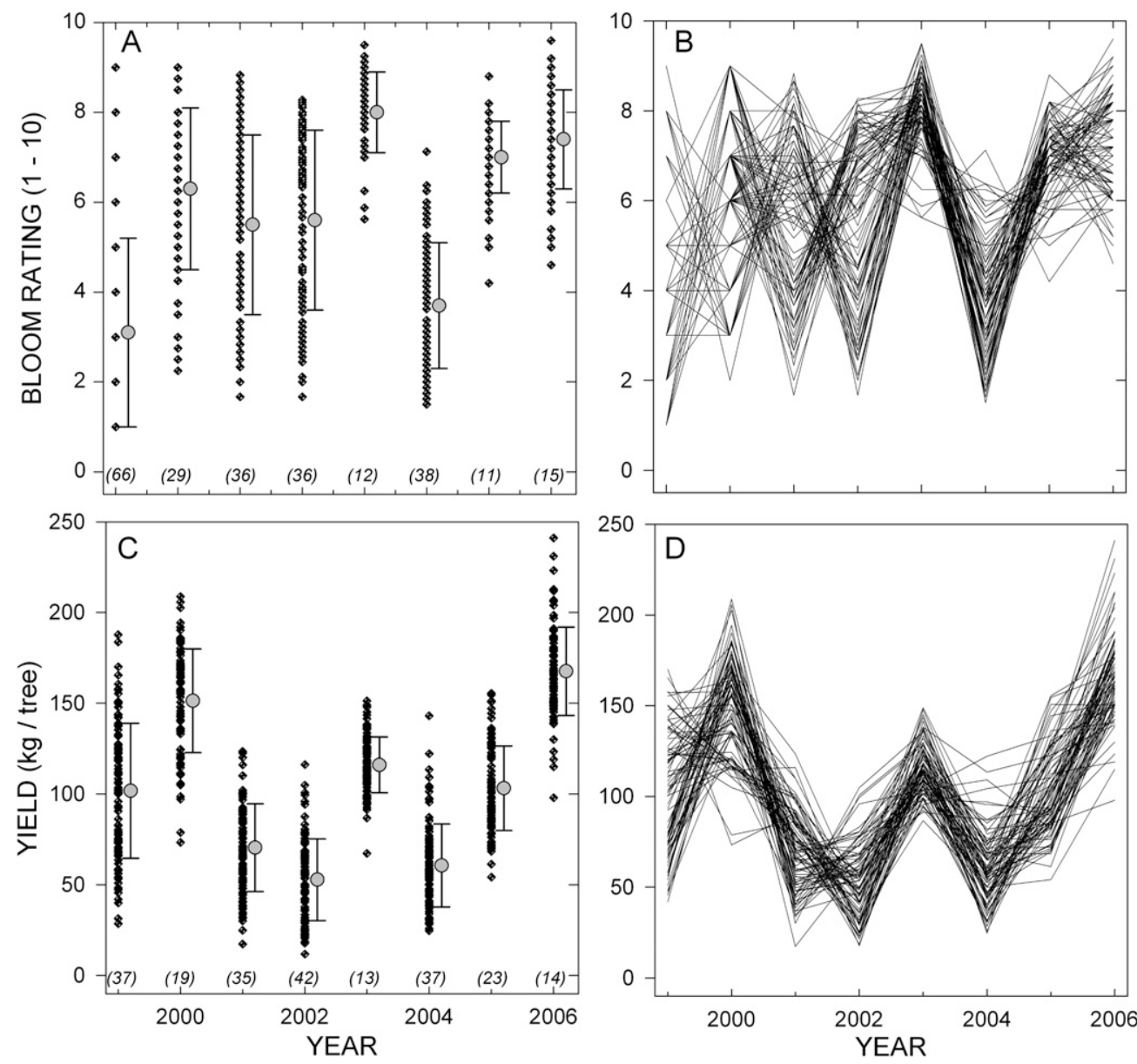

Fig. 5. Within-year dispersion and synchrony of bloom (above) and yield (below) among individual trees of a 'Delicious' apple population ( $\mathrm{n}=95)$ growing under identical environmental conditions and cultural practices. The single point and bar graphs in $\mathbf{A}$ and $\mathbf{C}$ present the mean and SD and values in parentheses the cvs; individual tree profiles in B and $\mathbf{D}$ illustrate the degree of synchrony. Data points for 1999 bloom rating are mean ratings; all other data points and lines are for individual trees.

report temporal and within-year variation in both BD and yield in a highly uniform tree population growing under identical environmental conditions and cultural practices over a 9-year period. We also relate our findings to flower initiation, fruit set, fruit size, and synchrony of the tree population. In the first year, we established a defined tree population $(\mathrm{n}=95)$ with a normally distributed fruit load (Fig. 1) as a basis for following the relationships between fruit load and flowering and fruiting of individual trees in subsequent years.

Temporal variation. The temporal profiles for $\mathrm{BD}$ and yield were similar (Fig. 2A), although the mean annual $\mathrm{CV}$ for bloom was $\approx 15 \%$ greater than for yield (Table 2 ). The annual patterns for both were irregular, but not biennial, because there were two 3-year periods (2000-2002 and 2004-2006) of insignificant annual alternation (Fig. 2A). There were 3 years of annual mean yields above and 3 below the general mean and 4 above and 3 below the general mean for $\mathrm{BD}$ (Fig. 2A). BD for the remaining years was on or near the general mean. This lack of biennality in this spur-type 'Delicious' population was similar to that reported for some other cultivars (Jonkers, 1979; Monselise and Goldschmidt, 1982). Although there was a late bloom frost (11 d after full bloom) in 2002, and the yield was the lowest (54 kg/ tree) in the study, it did not significantly affect the profile, because in 2 other frostfree years $(2001,2004)$, the mean annual yield was also similarly low, namely 62 and $69 \mathrm{~kg} /$ tree (Table 2; Fig. 2A).

The calculated intensity of annual fluctuation (I) was relatively low for both $\mathrm{BD}(0.01$ to 0.37$)$ and yield (0.04 to 0.37$)$ suggesting a moderate level of alternation in this population, because a value of 0 represents equal yield over 2 consecutive years and a value of 1 a crop versus no crop condition (Table 2; Fig. 2B). The I values also suggest a moderate level of synchrony among the trees, although this calculation is limited to only any 2 consecutive years (Hoblyn et al., 1936).

A similar irregular alternating cycle was also observed for fruit size, indexed by annual mean fruit weight, that was inversely related to yield (Fig. 3A). However, the percentage of large (70 to $82 \mathrm{~mm}$ ) and small (51 to $64 \mathrm{~mm}$ ) fruit, selected to represent commercially desired versus low-value fruit, was not consistently related to yield (Fig. 3B). There was no significant relationship when the small or large fruit fraction was regressed on yield. Considering the annual mean for fruit size overall years, $79 \% \pm 16 \%$ of the fruit was larger than $70 \mathrm{~mm}$ diameter and only $\approx 5 \%$ less than $57 \mathrm{~mm}$ diameter and less than $\approx 2 \%$ in 6 of the 8 years (Fig. 3B). Thus, this cultivar consistently (CV 20\%) partitioned reserves into large fruit over a threefold variation in yield (54 to $168 \mathrm{~kg}$ / tree). This may account for the poor yield/ large fruit relationship.

It is well established that excessive fruiting inhibits flower initiation leading to biennial bearing. Removal of fruit early after bloom (within $\approx 6$ weeks) generally reduces the inhibitory effect of fruit on flowering (Harley et al., 1942). Furthermore, seeded fruit inhibits flower initiation more than seedless fruit in some apple cultivars (Chan and Cain, 1967), and this effect appears to be related to a source of hormones (e.g., GAs) known to inhibit flowering in apple (Dennis and Neilsen, 1999; Guttridge, 1962; Hedden et al., 1993; Luckwill et al., 1969). These data provide convincing evidence for a direct role of the fruit/seed in flower initiation. The temporal profiles of our data for yield and BD generally support a close negative relationship between fruit load and flower initiation (Fig. 2A). Regressing flower initiation, indexed by return bloom, on yield (weight of fruit/tree) over the course of the study indicated that $39 \%$ of the total sums of 


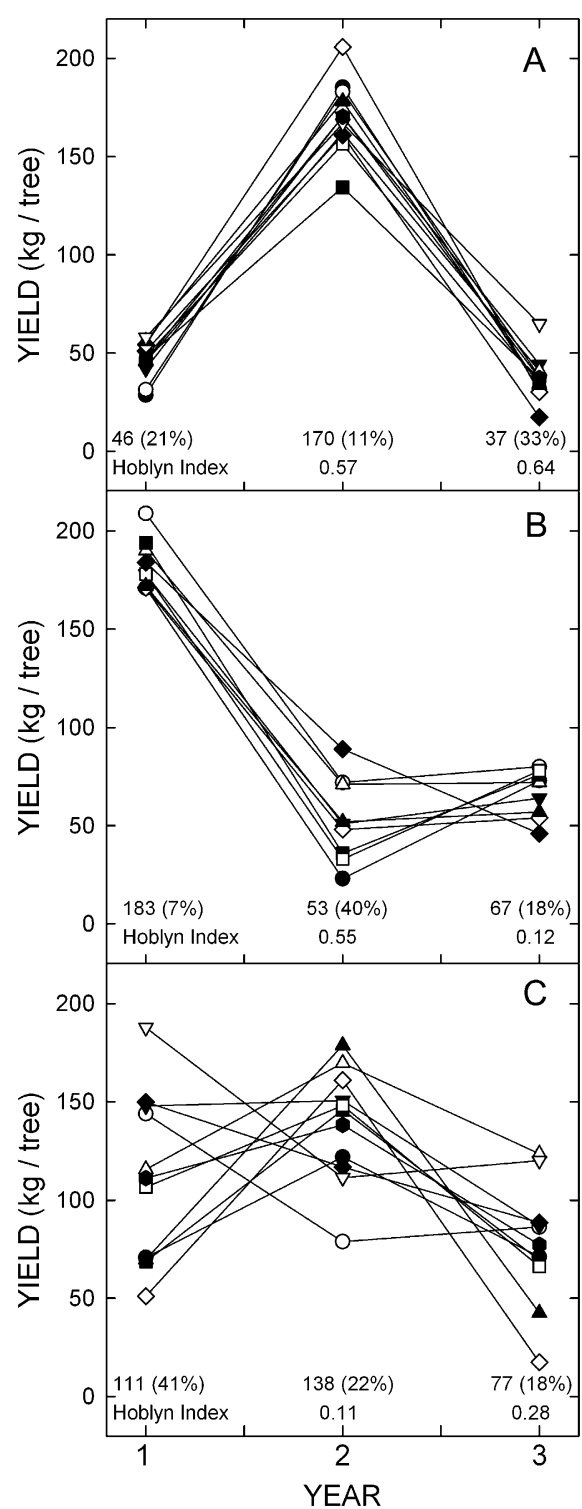

Fig. 6. Individual tree yield profiles of subpopulations of 'Delicious' trees illustrating the relationship between high (A-B) and low $(\mathbf{C})$ synchrony at various crop levels in Year 1 and annual cropping. The values are the mean yield and $\mathrm{cv}$ in parenthesis.

squares could be accounted for by regression $\left(r^{2}=0.39, P=0.10\right)$, but low annual flower initiation was not consistently associated with high yields (Table 2). However, ignoring the annual cycle and comparing flower initiation only on trees with the three lowest versus highest annual yields showed that the BD rating decreased from 6.9 to 4.3 as yield increased from 62 to $136 \mathrm{~kg} /$ tree, respectively. Thus, flower initiation was $60 \%$ greater on trees with $54 \%$ less fruit. Assuming that each $\mathrm{BD}$ unit represents 1000 flowers, then the low-yield trees initiated $\approx 112$ flowers and high-yield trees $\approx 32$ flowers per kilogram of fruit. Flower initiation was more closely related to fruit number than to fruit weight per tree. The regression of flower initiation on number of fruit gave an $r^{2}$ of $0.52(P=0.043)$. Interestingly, the $r^{2}$ for flower initiation on seed number per tree $\left(r^{2}\right.$ of $0.43, P=0.076$ ) was higher than that for weight of fruit, but less than that for number of fruit. One explanation for the lower value for seed number may be related to seed abortion. We counted only viable seeds per fruit at harvest. A greater number of viable seeds were probably present at the time of flower initiation, providing a source of the proposed inhibitor, but some seeds aborted between time of flower initiation and harvest, and thus our count underestimated viable seed number at the time of initiation. Martin et al. (1964) found cell number in the cortex related to fluctuation in yield. Seed number per fruit was not correlated with annual yields. These findings were from a limited sample on 30-year-old 'Jonathan' trees induced to biennial bearing by severe drought.

Within-year variation and synchrony. Both variation and synchrony are expressed at the individual tree level and, therefore, the individual trees generate the characteristics of the population (Lamontagne and Boutin, 2007). Thus, we focused on flower initiation and yield of individual trees in the population for this and several additional reasons. $\mathrm{Nu}-$ merous studies with apple have established marked variations in fruiting behavior of individual trees. Even subunit of apple trees, e.g., major branches and spurs, may become asynchronous naturally by environmental and biotic stresses or asynchrony can be induced by early deflowering or defruiting. These units remain autonomous and exhibit an alternate/biennial habit that persists for several consecutive years before becoming in-phase with the remainder of the tree (Harley et al., 1942). Based on visual observations, alternate within-tree variation was not apparent in our population.

There was considerable variation among individual trees in central tendency, range, and skewness in both BD and yield as illustrated in the within-year relative frequency histograms (Fig. 4). Generally, the range, in any given year, was greater for BD than for yield. This may be related to flower quality/fruit set limitations often associated with trees having excessive bloom or to efficiency of pollination. Pollination efficiency should not have been a factor, because we provided bees, and pollen from several apple cultivars was available in the same orchard Also, there was no consistent relationship between tree frequency distribution between $\mathrm{BD}$ and yield relative to crop load, e.g., Fig. $4 \mathrm{C}-\mathrm{D}$ versus $\mathrm{O}$ and $\mathrm{P}$ for high-yield trees ( 150 and $168 \mathrm{~kg} /$ tree) or $\mathrm{E}$ and $\mathrm{F}$ versus $\mathrm{K}$ and $\mathrm{L}$ for low yields (69 and $62 \mathrm{~kg} /$ tree). The absence of biennality in BD and yield in 2004 to 2006 may be related to allocation of resources (Iwasi et al., 1997), where reserves were accumulated in the 3 previous years (2003 to 2005) with below average yields (93 $\mathrm{kg} /$ tree) and then used in cropping in 2006 (Fig. 5). A similar period of consistently lower BD occurred during 2000 to 2002 (yield not included because of a possible effect of frost).

Synchrony was low and individual tree variation was high for both $\mathrm{BD}$ and yield (CV of $66 \%$ and $37 \%$ ) in the first year (1999) after establishing the population (Fig. 5) with a wide range in crop load the previous year (Fig. 1). During the next 3 years, variation remained high and in 2003, the population became highly synchronized with unusually low tree variation of $\mathrm{CV} 12 \%$ for $\mathrm{BD}$ and $13 \%$ for yield (Figs. 5A and C). Thereafter, variability began to increase again. This sequential shift can be explained, in part, by the high variation in fruit load (Fig. 1) with its corresponding inhibition of flower initiation; this lack of synchrony persisted for BD, but trees became synchronized more quickly for yield (Figs. 5B and D). Other inherent factors are probably also involved in reestablishing an equilibrium (homeostasis) between fruiting and flowering. No cultural practices or environmental factors in our study could be associated with this shift with the possible exception of temperature (Table 1). There was a light frost in 2002, but this was an unlikely factor, because the trees became highly synchronized before the frost (Fig. 5D).

Individual tree variation and synchrony are two factors affecting native cropping patterns (Koenig et al., 2003). Individual tree variation was not a factor in our study. However, synchrony and temporal changes in synchrony were related to irregular cropping (Fig. 5). Based on fruit load effects on flower initiation and subsequent yield, trees with a low or high crop load and highly synchronized should favor a strong biennial bearing habit. In contrast, trees with low synchrony and moderate yield would be expected to favor annual cropping. A strong biennial cropping pattern was observed in the highly synchronized (CV 21\%) and lowyielding (Year 1) subpopulation in our study (Fig. 6A). In comparison, the subpopulation selected for high synchrony ( $\mathrm{CV} 7 \%$ ) and the high yield also exhibited a strong biennial effect, but less so in the second cropping cycle (Fig. 6B). The mean yields over three cropping cycles for these two populations were 84 and $94 \mathrm{~kg} /$ tree, respectively. The subpopulation selected for low synchrony ( $\mathrm{CV}$ $41 \%$, mean yield $111 \mathrm{~kg} /$ tree) had a family of crop load profiles showing both inhibition and promotion of flower initiation (Fig. 6C), thus a tendency for regular cropping. These data also suggest that a yield of $\approx 100 \mathrm{~kg} /$ tree with low synchrony covers a threshold for fruit load effect on flower initiation in these 'Delicious' trees.

The significant native variation found in both $\mathrm{BD}$ and yield poses a challenge in selection of trees for research in which yield is used as an index of response (e.g., fruit thinning). To illustrate, a population of highly uniform trees at bloom (BD 9, SD 15, CV 12\%, range 8.5 to $9.5 \mathrm{BD})$ was present in the most uniform population of this study (Fig. 5A, 2003). If one selects trees from this population for an experiment, the mean yield would have been $119 \mathrm{~kg} /$ tree, SD 15 , and CV $13 \%$, and yield would have ranged from 61 to 150 $\mathrm{kg} /$ tree without any treatment. It would require 30 replications to demonstrate a $10 \%$ 
difference, or 12 replications for a $15 \%$ difference at $\alpha=0.05$. Thus, recognition of the natural variation is extremely important in experimental design of such studies not only in providing an understanding of irregular bearing, but also for increasing the precision of studies designed to regulate cropping patterns.

\section{Literature Cited}

Aldrich, W.W. and L.A. Fletcher. 1932. Relation of foliage system and fruit thinning to biennial bearing in apples. Proc. Amer. Soc. Hort. Sci. 29:56-61.

Bobb, A.C. and M.A. Blake. 1938. Annual bearing in the Wealthy apple was induced by blossom thinning. Proc. Amer. Soc. Hort. Sci. 36:321327.

Brown, G.G. 1942. How long does the influence of thinning Yellow Newtown apple trees last? Proc. Amer. Soc. Hort. Sci. 40:99-102.

Buban, T. and M. Faust. 1982. Flower bud induction in apple trees: Internal control and differentiation. Hort. Rev. (Amer. Soc. Hort. Sci.) 4:174-203

Bukovac, M.J., P. Sabbatini, and P.G. Schwallier. 2006. Modifying alternate bearing of spur-type 'Delicious' apple with ethephon. HortScience 41:1606-1611.

Buonaccorsi, J.P., J. Elkinton, W. Koenig, R.P Duncan, D. Kelly, and V. Sork. 2003. Measuring mast seeding behavior: Relationships among population variation, individual variation and synchrony. J. Theor. Biol. 224:107114.

Chan, B.G. and J.C. Cain. 1967. The effect of seed formation on subsequent flowering. Proc. Amer. Soc. Hort. Sci. 91:63-68.

Davis, L.D. 1957. Flowering and alternate bearing. Proc. Amer. Soc. Hort. Sci. 70:545-556.

Dennis, F.G., Jr. 2000. The history of fruit thinning. Plant Growth Regulat. 31:1-16.

Dennis, F.G. and J.C. Neilsen. 1999. Physiological factors affecting biennial bearing in tree fruit:
The role of seeds in apples. HortTechnology 9:317-322.

Drain, B.D. 1924. Annual crops from biennial bearing apple trees. Proc. Amer. Soc. Hort. Sci. 21:300-302.

Fulford, R.M. 1960. The use of defoliating sprays for the control of biennial hearing in apple. $\mathrm{J}$. Hort. Sci. 35:202-213.

Guttridge, C.G. 1962. Inhibition of fruit-bud formation in apple with gibberellic acid. Nature 196:1008.

Harley, C.P., J.R. Magness, M.P. Masure, L.A. Fletcher, and E.S. Degmon. 1942. Investigations on the cause and control of biennial bearing of apple trees. USDA Tech. Bul. 792.

Harley, C.P., M.P. Masure, and J.R. Magness 1935. Fruit thinning and biennial bearing on individual main leaders of Yellow Newton apples. Proc. Amer. Soc. Hort. Sci. 32:4346.

Hedden, P., G.V. Hoad, P. Gaskin, M.J. Lewis, J.R. Green, M. Furber, and L.N. Mander. 1993. Kaurenoids and gibberellins, including the newly characterized gibberellin A88, in developing apple seeds. Phytochemistry 32:231237.

Herrera, C.M. 1998. Population-level estimates of interannual variability in seed production: What do they actually tell us? Oikos $82: 612$ 616.

Hoad, G.V. 1978. The role of seed derived hormones in the control of flowering in apple. Acta Hort. 80:93-103.

Hoblyn, T.N., N.H. Grubb, and A.C. Painter. 1936. Studies in biennial bearing. I. J. Pomol. 14:3976.

Iwasi, Y., K. Sugimura, A. Sumida, and H. Ito. 1997. How does masting happen and synchronize? J. Theor. Biol. 187:231-239.

Jackson, J.E. and P.J.C. Hamer. 1980. The causes of year-to-year variation in the average yield of Cox's Orange Pippin apple in England. J. Hort. Sci. 55:149-156.

Jonkers, H. 1979. Biennial bearing in apple and pear: A literature survey. Sci. Hort. 11:303317
Kelly, D. and V.L. Sork. 2002. Mast seeding in perennial plants: Why, how, where? Annu. Rev. Ecol. Syst. 33:427-447.

Koenig, W.D., D. Kelly, V.L. Sork, R.P. Duncan, J.S. Elkinton, M.S. Peltonen, and R.D. Westfall. 2003. Dissecting components of populationlevel variation in seed production and the evolution of masting behavior. Oikos 102:581-591.

Lamontagne, J.M. and S. Boutin. 2007. Local-scale synchrony and variability in mast seed production patterns of Picea glauca. J. Ecol. 95: 991-1000.

Lombardo, J.A. and B.C. McCarthy. 2008. Silvicultural treatment effects on oak seed production and predation by acorn weevils in southeastern Ohio. For. Ecol. Mgt. 255:2566-2576.

Luckwill, L.C. 1977. Growth regulators in flowering and fruit development, p. 293-308. In: Plimmer, J.R. (ed.). Pesticide chemistry in the 20th century. Amer. Chem. Soc. Sym. Series 37, Washington, DC.

Luckwill, L.C., P. Weaver, and J. Macmillan. 1969. Gibberellins and other growth hormones in apple seeds. J. Hort. Sci. 44:413-424.

Martin, D., T.L. Lewis, and J. Cerny. 1964. Apple fruit cell numbers in relation to cropping alternation and certain treatments. Aust. J. Agr. Res. 15:905-919.

McArdle, B.H. and K.J. Gaston. 1995. The temporal variability of densities: Back to basics. Oikos 74:165-171.

McCarthy, B.C. and J.A. Quinn. 1989. Within- and among-tree variation in flower and fruit production in two species of Carya (Juglandaceae). Amer. J. Bot. 76:1015-1023.

Monselise, S.P. and E.E. Goldschmidt. 1982 Alternate bearing in fruit trees. Hort. Rev. (Amer. Soc. Hort. Sci.) 4:128-173.

Singh, L.B. 1948a. Studies in biennial bearing. II. A review of the literature. J. Hort. Sci. 24:45-65.

Singh, L.B. 1948b. Studies in biennial bearing. III Growth studies in 'on' and 'off' year trees. J. Hort. Sci. 24:123-148.

Sparks, D. 1983. Alternate fruit bearing in nut trees. Ann. Rept. North. Nut Gro. Assoc. 74:197-230. 